\title{
Consideraciones acerca de la aptitud urbana en la provincia de Buenos Aires -Dos fenómenos contrapuestos $-(*)$
}

\section{POR RICARDO PABLO RECA (**)}

\begin{abstract}
Sumario: I. Palabras previas.- II. Un palmario diagnóstico.- III. El ordenamiento territorial.- IV. Un modelo territorial.- V. Un inapelable testimonio.- VI. Sobre la aptitud urbana.- VII. Otros aspectos a considerar.- VIII. Bibliografía.
\end{abstract}

Resumen: el ordenamiento territorial en nuestra provincia de Buenos Aires y las imprescindibles normas, principios y técnicas asociadas a su implementación, exponen una severa e insoluble anomia; desplazando, entre otros tópicos esenciales, la clasificación y ocupación del suelo, favoreciendo de este modo, la aparición de dos fenómenos urbanos; cuyo constante crecimiento refleja distintas y complejas disfuncionalidades. Ante esta injustificada carencia, resulta necesario detenerse en el concepto de aptitud urbana como una condición fundamental de nuestro derecho a la ciudad, expectativa que, en nuestro caso, se agrava aún más, por la imposibilidad de dictar las respectivas cartas locales.

Palabras claves: anomia territorial - ausencia de planificación - barrios cerrados - asentamientos informales - crisis municipal

\section{Considerations about urban in the province of Buenos Aires}

\section{-Two opposing phenomena-}

Abstract: the territorial order in our Province of Buenos Aires and the essential rules, principles and techniques associated with its implementation, expose a severe and insoluble anomie, displacing, among other fundamental topics, the classification

(*) El presente trabajo, para dar cumplimento a las Pautas editoriales respecto a cantidad de páginas, será publicado en su versión completa en el formato electrónico. Agradezco especialmente la colaboración de la becaria María Celeste Teves.

(**) Doctor en Derecho, Universidad Complutense de Madrid, España. Prof. Titular Cátedra I Derecho Público, Provincial y Municipal y Dir. del Instituto de Política y Gestión Pública, Facultad de Ciencias Jurídicas y Sociales, Universidad Nacional de La Plata, UNLP. 
and ocupation of the ground, favoring, therefore, the appearance of two urban phenomena, whose constant growth has different and complex dysfunctionalities. Faced with this unjustified lack, it is necessary to consider the notion of urban aptitude as an essential condition for our right to the city, an expectation that, in our case, is further aggravated by the impossibility of dictating the respective local constitutions.

Keywords: territorial anomie - lack of planification - gated communities - informal settlements - municipal crisis

\section{Palabras previas}

Resulta difícil abordar un tema, que lamentablemente ha sido desplazado en el horizonte público bonaerense. Una serie de factores, que hemos señalado a lo largo de los años, han menoscabado el plexo jurídico llamado a tutelar una política sobre el territorio (Reca, 2002).

Así lo expone en explícito lenguaje, el marco jurídico que rige la cuestión; que, entre otras normas básicas, refieren a la Ley Orgánica de las Municipalidades (1958); la Ley de ordenamiento territorial y uso de suelo (1977) y la Ley sobre el régimen de los inmuebles del Dominio municipal y provincial (1980); un cuerpo normativo producto de otras instancias institucionales, que ha quedado claramente desmoronado durante esta etapa democrática.

Efectivamente, los preceptos aludidos ponen de manifiesto que en estos 35 años de vida cívica no hubo reformas significativas, aspecto que inicialmente nos exhibe un cuadro de situación que ha estado orientado en las últimas décadas a otros propósitos, ya sean nuevas expresiones territoriales (barrios cerrados) o a una necesidad política guiada por las más urgentes demandas sociales (asentamientos informales) como reflejo de las actividades predominantes.

Por otra parte, los tópicos vinculados al ordenamiento territorial, deberían conjugarse con otros principios rectores que reflejan una nueva generación de derechos colectivos. Así lo plasma nuestra Constitución provincial ( $\nu$.gr: cláusula de medioambiente; mecanismos de participación, etc.) todos ellos imprescindibles propuestas, que como bien conocemos, han tenido una morosa respuesta en el terreno de su efectiva aplicación.

Pareciera haber prevalecido una "razonabilidad política" que se desentendió de la operatividad de estos principios en alarmante ciénaga, como lo demuestra el inofensivo epílogo del artículo 28 (medio ambiente) de nuestra Carta bonaerense, cuando después de una profusa enumeración de misiones y objetivos, establece que toda persona física o jurídica cuya acción u omisión pueda degradar el ambiente 
está obligada a tomar todas las precauciones para evitarlo; inocua definición que traduce una voluntad condicionada empañando el alcance de todo el artículo(1).

Lo mismo ocurre con las modalidades de participación, implementadas en tibios y excepcionales ensayos a nivel local o la propia ley de medioambiente (ley № 11.723/95)(2), que se desagrega del territorio en una peligrosa dicotomía, desconsiderando el concepto del medio ambiente urbano (MAU), principal eje de la materia de estudio.

En una palabra, un cuarto de siglo después, en esta materia tenemos un tejido constitucional insinuante que sin articulación alguna se superpone con las normas precitadas.

En este panorama, tampoco podemos obviar el pavoroso anacronismo de nuestro municipio, que como sabemos se acentuó en la inédita omisión de nuestra Convención Constituyente del año 94 (Reca, 2015).

Economizaremos en estas líneas lo mucho que genera este absurdo retraso, que en todo caso puede sintetizarse en la siguiente inquietud: ¿Cómo puede cumplir el municipio la responsabilidad primaria en el OT, si está huérfano de las competencias y organización que esta encomienda presume?

Sin duda, esta insólita falencia en nuestra Carta provincial ha condicionado el andamiaje público estatal, al desconocer las claras atribuciones que el constituyente nacional reconoció al municipio de forma inequívoca (artículo 123) contaminado todo el plexo normativo que rige la materia y en especial la potencialidad política, administrativa y financiera de los gobiernos locales.

Sobre esta omisión constitucional Losa (1995) advertía que la Constitución provincial, por su parte, en su reforma de 1994 no innovó en lo atinente al régimen

(1) Artículo 28: Los habitantes de la Provincia tienen el derecho a gozar de un ambiente sano y el deber de conservarlo y protegerlo en su provecho y en el de las generaciones futuras (...) asimismo, asegurará políticas de conservación y recuperación de la calidad del agua, aire y suelo compatible con la exigencia de mantener su integridad física y su capacidad productiva, y el resguardo de áreas de importancia ecológica, de la flora y la fauna. Toda persona física o jurídica cuya acción u omisión pueda degradar el ambiente está obligada a tomar todas las precauciones para evitarlo.

(2) Artículo 1: La presente ley, conforme el artículo $28^{\circ}$ de la Constitución de la provincia de Buenos Aires, tiene por objeto la protección, conservación, mejoramiento y restauración de los recursos naturales y del ambiente en general en el ámbito de la Provincia de Buenos Aires, a fin de preservar la vida en su sentido más amplio; asegurando a las generaciones presentes y futuras la conservación de la calidad ambiental y la diversidad biológica. Artículo 3: Los habitantes de la Provincia tienen los siguientes deberes: Inciso a): Proteger, conservar y mejorar el medio ambiente y sus elementos constitutivos efectuando las acciones necesarias a tal fin. Inciso b): Abstenerse de realizar acciones $u$ obras que pudieran tener como consecuencia la degradación del ambiente de la provincia de Buenos Aires. 
municipal, no obstante haber sido este aspecto contemplado entre los sujetos a revisión conforme los términos de la convocatoria de la Convención Constituyente, y a pesar de haber sido sancionada el 13 de septiembre de 1994, esto es, con posterioridad a la publicación de la reforma de la Constitución Nacional en el Boletín Oficial (23 de agosto de 1994), y esta falta de adecuación a la Ley Suprema de la Nación tiñe de inconstitucionalidad no sólo aquella reforma, sino también a toda norma que viole la autonomía municipal. Más aún: ¿Qué ocurrirá si un Municipio bonaerense, reivindicando su autonomía dicta su propia carta orgánica? Indudablemente la reforma ha sido poco feliz en este aspecto, pues dejó pasar una ocasión adecuada para receptar el moderno concepto de Municipio y, lo que es más grave, va a generar un caos jurídico, pues múltiples serán seguramente los conflictos que surgirán por la no adecuación —repito— de la Constitución provincial, a la Ley Suprema.

En consecuencia, todas las implicancias que presume el OT, su naturaleza pública, la configuración y organización del territorio, sus objetivos y estrategias, la implementación de políticas, el proceso de planificación y sus propósitos sociales, quedan traumáticamente desplazados por el anacronismo aludido.

\section{Un palmario diagnóstico}

Un reciente trabajo de tesis doctoral sobre "las políticas municipales del ordenamiento territorial en el ámbito de la provincia de Buenos Aires en el período 2003-2015" (Licia Ríos, 2017)(3) expone palmariamente este diagnóstico, en un preciso y lúcido relevamiento que nos ofrece algunos ejemplos:

- Señala la autora, que del total de temas gestionados (551) en articulación con el nivel provincial, solo un mínimo porcentaje (8\%) se corresponde con los de tipo integral, apenas 15 municipios lograron crear planes de OT, de los cuales 11 son del interior y 4 metropolitanos.

- También observa que la mayoría de los municipios (126), no tuvieron ningún tipo de previsión para la creación de áreas de reservas para el crecimiento urbano, a pesar del fuerte impulso que se dio a la inversión en vivienda social.

- Se detiene en el análisis de las capacidades específicas (administrativas, políticas y de planificación y gestión), en cuyo relevamiento se examinan numerosas ordenanzas (509) sancionadas bajo el vigente marco legal (decreto ley № 8.912/77), la mayoría vinculadas a la resolución de problemáticas parciales y

(3) Licia Ríos, Mg (2017). Capacidades estatales y políticas de ordenamiento territorial - Municipios de la Provincia de Buenos Aires en el contexto pos-neoliberal (2003-2015). Dirigida por el Arquitecto Bono, N., (FAU) de la Universidad Nacional de La Plata. Jurados: Profesor David Kullock (UBA), Doctora Isabel Martínez San Vicente (UNR) y Ricardo Pablo Reca (UNLP). 
las otras (relacionadas con la planificación y gestión), en gran parte para salvar errores de ordenanzas anteriores.

- En relación con este tema, advierte que los municipios pertenecientes al territorio metropolitano tuvieron más dificultades para desarrollar acciones vinculadas al OT, en tanto la mayor parte de las actuaciones fue movilizada para localizar urbanizaciones cerradas, como lo exponen las diversas resoluciones ministeriales (307), obrantes en el registro provincial de las mismas. También destaca que no existieron actuaciones interjurisdiccionales o un proyecto de territorio metropolitano que enmarque las acciones parciales.

- En cuanto al sistema de ordenamiento y en particular el subsistema jurídico, que regula las acciones vinculada a esta política, señala, que, entre otras orfandades, no existe un instrumento específico (a pesar de alguna iniciativa) y solamente el marco que rige la materia ambiental establece algunas pautas de incidencia sobre este tema, que hasta el momento ha tenido como referencia simbólica el fallo judicial del caso Mendoza (4).

- Equivalente panorama se ofrece con el decreto № 8.912/77 (sobre el uso, ocupación y subdivisión de suelo) que desconoce la diversidad de situaciones territoriales de los municipios bonaerenses y su marco de aplicación resulta acotado a muy pocos casos.

- Respecto al sistema de planificación tampoco se ha plasmado norma alguna y su implementación (principalmente orientada a la organización de la inversión federal de la estructura y equipamiento), queda a expensas de la voluntad política de algunas pocas administraciones.

- En este cuadro de situación, menciona como excepciones el caso de los municipios de Malvinas Argentinas (se sancionaron 10 ordenanzas vinculadas al OT) y la localidad de Tandil (en este caso fueron 13) y subraya como un rasgo predominante, los ejes estratégicos que definieron el proyecto del territorio y la continuidad política en ambos municipios.

- Para concluir, que desde el punto de vista urbano territorial, en el periodo se destacan los procesos de expansión urbana en forma de urbanizaciones cerradas periféricas; la extensión y densificación de las tipologías de hábitat popular informal; y la consolidación de políticas de hábitat descoordinadas de la planificación urbana y territorial.

(4) Mendoza, Beatriz Silvia y otros c/ Estado Nacional y otros s/ daños y perjuicios (daños derivados de la contaminación ambiental del Río Matanza - Riachuelo). CSJN. Año 2008. 


\section{II.1. La necesidad de una política de Estado}

Se suma a esta lacónica perspectiva, la ausencia de una ley marco de ordenamiento territorial en el plano nacional (5). Sin perjuicio de los motivos que hayan obstaculizado su materialización y más allá de su valor como antecedente, podemos conjeturar que esta primordial carencia ya no se trata de la dicotomía en que parecen desenvolverse los estilos predominantes que caracterizan la marcha del Estado, pues el país ha recorrido en los últimos lustros ambas concepciones y en la cuestión en análisis podemos observar equivalentes efectos.

Hay una cuestión subyacente que no ha sido abordada con el rigor que merecería, vivimos una emergencia consuetudinaria que ha desarticulado toda la organización jurídica-institucional, impregnando de nuevas modalidades esta cultura de la coyuntura.

Tendencia que se instauró a principios de los años 90 en el marco de la privatización, desregulación y racionalización del Estado, salvoconducto de una inercia eficientista que caracterizó la gestión(6).

Pues bien, a lo largo de los últimos 25 años la emergencia se ha convertido en una regla invisible, en una desconstrucción normativa, que por la fuerza de su propia génesis asume la "inauguración" como referencia excluyente de su estilo.

Esto es justamente la contracara de una "política de Estado" que presume coincidencias sustanciales sobre temas prioritarios, generando un marco institucional donde se infiere la interpretación y la agonal tensión que define la política (7) (Reca, 1999-2013).

(5) Uno de los obstáculos más significativos para abordar este delicado tema, es la inexistencia de leyes de ordenamiento territorial. Un último intento en la materia fue el "Plan Argentina 2016, Politica y Estrategia Nacional de Desarrollo y Ordenamiento Territorial -PEN-Ministerio de Planificación Federal.

(6) Durante la década del 90 se llevó a cabo un proceso de desregulación, donde el Estado cedió el poder relativo y el mercado "acentúa su accionar" en materia de desarrollo urbano. Como mecanismo de gestión, la planificación urbana y territorial fue disminuyendo, así como también las capacidades de intervención desde el Estado.

Estos procesos de urbanización sin planificación, han producido una serie de externalidades negativas tanto en las ciudades mismas como en los marcos institucionales y las estructuras de gobernanza y las dinámicas sociales, económicas y ambientales urbanas (CEPAL y ONU-Hábitat, 2016).

(7) Si se nos permite la licencia, el Estado debiera ser siempre empresario de la correcta utilidad que le asigne a los recursos sociales. Debiera ser siempre benefactor en el adecuado amparo de las condiciones de indigencia y marginalidad que requieran de su básica asistencia. Debiera ser siempre interventor en la imprescindible intermediación que implica la puja de los heterogéneos intereses que componen la malla social. Y desde ya el Estado debiera ser siempre de Derecho, en tanto 
No es extraño, entonces, que el tema del OT junto a otras trascendentes materias, navegue en estas aguas insinuantes, que forman parte del catálogo de promesas que nuestra dirigencia declama con periódico fervor.

A medida que pasa el tiempo, una silenciosa involución aleja esta materia de la agenda pública, nuevos imponderables van exigiendo su inmediata atención, como el delicado tema de la exclusión social que no se agota en la cobertura de las necesidades básicas insatisfechas, sino que entre otros factores involucra directamente la cuestión en análisis. Los asentamientos informales, la falta de servicios públicos esenciales, la consolidación y aumento de estos, la ocupación de terrenos no aptos para el hábitat y un sinnúmero de aspectos ligados a este ligero relevamiento, van definiendo una geografía urbana que aumenta su complejidad y diversifica sus alternativas, distanciando las previsiones sobre el territorio que constituyen el propósito natural y determinante en esta materia. Podríamos seguir cuestionando esta severa falencia, pero ello poco contribuiría a una propuesta que justifique de algún modo estas líneas.

En definitiva, no hay un marco regulatorio y sólo los artículos 41 y 124 de nuestra Constitución Nacional (8) y la ley de medio ambiente No 25.675/02 (9) se ofrecen como referencia de este anómico panorama.

sujeción ordenadora de su propia actividad y regulación coercitiva de lo social. Por ello debemos darnos una discusión reveladora que permita ponernos de acuerdo sobre las razones primordiales que justifican y exigen intermediación estatal. En definitiva, no es la adjetivación lo que nos importa, sino el reconocimiento genuino de su función.

(8) Artículo 41: Todos los habitantes gozan del derecho a un ambiente sano, equilibrado, apto para el desarrollo humano y para que las actividades productivas satisfagan las necesidades presentes sin comprometer las de las generaciones futuras; $y$ tienen el deber de preservarlo. El daño ambiental generará prioritariamente la obligación de recomponer, según lo establezca la ley. Las autoridades proveerán a la protección de este derecho, a la utilización racional de los recursos naturales, a la preservación del patrimonio natural y cultural y de la diversidad biológica, y a la información y educación ambientales. Corresponde a la Nación dictar las normas que contengan los presupuestos mínimos de protección, y a las provincias, las necesarias para complementarlas, sin que aquéllas alteren las jurisdicciones locales (...). Artículo 124: Las provincias podrán crear regiones para el desarrollo económico y social y establecer órganos con facultades para el cumplimiento de sus fines y podrán también celebrar convenios internacionales en tanto no sean incompatibles con la política exterior de la Nación y no afecten las facultades delegadas al Gobierno federal o el crédito público de la Nación; con conocimiento del Congreso Nacional. La ciudad de Buenos Aires tendrá el régimen que se establezca a tal efecto.

(9) Artículo 2: La política ambiental nacional deberá cumplir los siguientes objetivos: a) Asegurar la preservación, conservación, recuperación y mejoramiento de la calidad de los recursos ambientales, tanto naturales como culturales, en la realización de las diferentes actividades antrópicas; b) Promover el mejoramiento de la calidad de vida de las generaciones presentes y futuras, en forma prioritaria; c) Fomentar la participación social en los procesos de toma de decisión; d) Promover el uso racional y sustentable de los recursos naturales; e) Mantener el equilibrio y dinámica de los sistemas ecológicos; f) Asegurar la conservación de la diversidad biológica; g) Prevenir los efectos 


\section{II.2. Una inevitable reflexión}

Entonces, debemos aportar un atisbo de solución, que en principio encuentre sus fuentes en los textos constitucionales provinciales, su desarrollo legislativo, lo previsto en el régimen municipal y en particular en sus Cartas orgánicas (10). No hay duda que allí debemos centrar nuestra atención, porque a falta de una propuesta en el orden nacional, cada jurisdicción asume esta materia estableciendo criterios propios de acuerdo con sus necesidades, características e idiosincrasia.

Pero como hemos visto, poco aportan los antecedentes bonaerenses, pues la ley No 8912 que sin duda reflejó un hito de singular importancia (Scotti, 1979)(11), desde hace años presenta un umbral muy bajo de aplicación, apenas como referencia en los actuados que exigen la supervisión provincial o en la legitimación de determinados emprendimientos.

Desde ya, no se trata de adosar esta insuficiencia a los agentes públicos responsables del área, sino de reconocer que una ley no se basta a sí misma, requiere un plexo normativo congruente, una organización administrativa acorde, una férrea y consensuada voluntad política que priorice su aplicación, una definida formación y una legitimación ciudadana que traduzca en expectativas y conductas su alcance.

Si estos elementos no están, la ley levita, se presenta famélica en su espíritu, extravía su efectividad, para finalmente languidecer frente a los hechos consumados.

Alcanza con recorrer nuestra provincia para corroborar la deficitaria estructura administrativa y técnica que tienen la mayoría de los municipios, los escasos

nocivos o peligrosos que las actividades antrópicas generan sobre el ambiente para posibilitar la sustentabilidad ecológica, económica y social del desarrollo; h) Promover cambios en los valores y conductas sociales que posibiliten el desarrollo sustentable, a través de una educación ambiental, tanto en el sistema formal como en el no formal.

(10) Como sabemos todas las provincias (con excepción de Mendoza y Santa fe) han dictado sus nuevas constituciones, consagrando con distintos matices el alcance de la autonomía municipal y criterios asociados al planeamiento del territorio y medioambiente. En el caso de las Cartas Orgánicas se han dictado en el país 171, de las cuales tomaremos como ejemplo en este trabajo el de la ciudad de Córdoba.

(11) Nos dice Scotti "la ley No 8912 es la primera en su tipo a nivel nacional o provincial, que ha venido a regular la compleja problemática del urbanismo y el planeamiento, a fin de establecer pautas adecuadas al desordenado crecimiento actual de las poblaciones. Resulta claramente apreciable el vacío que viene a llenar la ley № 8912, como la inacción del Estado en las últimas décadas, observando la legislación anteriormente vigente y que se deroga. Las principales normas que han sido suplantadas, según se menciona en el artículo 104º, son la ley 695 del año 1870 y la ley 3487 del año 1913. Por lo expuesto, para comprender los principios de la nueva legislación es necesario profundizar su filosofía y aislarse de todo cuanto regía anteriormente en la provincia o el país" (1979). 
recursos con que cuentan y la inestabilidad de un equipo para implementar las distintas ordenanzas sobre la materia.

En este sentido, vale recordar la manera en que se aprobó nuestro código urbanístico en la ciudad de La Plata, para enfatizar que fue una sesión reservada, que terminó judicializando sus alcances por las graves falencias en su texto, cuestión que revelaron los diarios del momento y los diversos testimonios y actuaciones de las ONG involucradas (Reca, 2012).

En la estructura provincial se reproduce en escala este panorama, que como hemos referido no depende únicamente de los agentes públicos formados en el tema (el trabajo de tesis citado nos provee una muestra) pues, el nivel de decisión en la provincia apenas puede desenvolverse sobre parámetros verificables, pero poco puede hacer sobre situaciones de inminente naturaleza política, como el incremento de los numerosos asentamientos informales.

Así, en un reciente relevamiento de la ONG Techo (año 2016), surge que más de la mitad de las personas que habitan asentamientos informales o villas viven en la provincia de Buenos Aires. Allí se contabilizaron 397.705 familias (en 1352 asentamientos); le sigue la Capital, con 82.585; Rosario con 49.475 .

En este sentido, la ley del hábitat ( No 14.449/12) en su artículo 27 define ambas modalidades de asentamiento de la siguiente manera:

b) Villas: urbanizaciones o auto urbanizaciones informales producto de ocupaciones de tierra urbana vacante o de la afectación de tierras fiscales por el Estado para asentar a familias provisoriamente, cuyas características son que: producen tramas urbanas irregulares, no son barrios amanzanados sino organizados en intrincados pasillos, las viviendas son construidas con materiales precarios o de desecho, cuentan con alta densidad poblacional y con escaso o nulo espacio verde e infraestructura auto provista.

c) Asentamientos precarios: aquellos barrios informales en los que sus trazados urbanos tienden a ser regulares y planificados, son generalmente decididos y organizados colectivamente, están ubicados en su mayoría sobre tierra degradada, los ocupantes buscan legitimarse como propietarios, las viviendas tienen algún nivel de firmeza, se han reservado espacios públicos para plazas y otros equipamientos y se han ido formalizando paulatinamente las redes de servicios públicos.

Hechas estas aclaraciones, nos referiremos al ordenamiento territorial con el afán de subrayar la necesidad de este importante tema y afirmar estos largos años que nos han involucrado con intensidad en la cuestión. 


\section{El ordenamiento territorial}

Debemos partir de la base que el ordenamiento territorial se presenta como un concepto amplio, que tiene la aspiración de integrar en el territorio las funciones estáticas y dinámicas de la vida social (actividades económicas, medios de comunicación, uso del suelo, espacios recreativos, naturales, etc.) (12) y que como tal se expresa en una técnica de actuación política, jurídica y administrativa.

Desde ya, esta técnica de actuación se ajustará, entre otras condiciones, a la idiosincrasia, morfología y naturaleza del territorio donde se implementará. Ello incluye naturalmente el sistema político, la legislación vigente en materia de fondo (en particular el régimen de propiedad y sus distintas limitaciones) y aspectos socioeconómicos y culturales íntimamente vinculados con la cuestión. Esta multiplicidad de actores (jurisdicciones), instrumentos (sistema jurídico) y factores, constituyen un horizonte que presume la dimensión sistémica de la materia y en consecuencia su imprescindible conexión con otras áreas afines de incidencia sobre el territorio (13).

\section{III.1. El medio ambiente urbano}

De esta manera, debemos concebir el OT con el alcance ambiental, pues en el marco de las ciencias no jurídicas (geografía, ecología y demás disciplinas naturales) carece de sentido plantearse aisladamente la temática del medioambiente y la del territorio, tanto si se enfoca este último en su dimensión meramente topográfica (tierra, suelo, superficie, paisaje o espacio), como en su consideración de soporte de actividades sociales (agrícolas, industriales, urbanas, de transporte o de recreo). Y ello por cuanto, desde un punto de vista ecológico, el territorio, junto

(12) Al parecer, la expresión ordenación del territorio se consolidó, a raíz de una serie de seminarios organizados por la ONU y la UNESCO entre 1958 y 1964, para designar el intento de integración armoniosa de las planificaciones de tipo físico, social y económico, con el fin de lograr el máximo bienestar de la población. Desde los puntos de vista científico y técnico, la ordenación del territorio constituye una fase de unión entre disciplinas económicas y urbanísticas, propiciada también por la pujanza analítica y operativa de la Geografía humana (López Ramón, 1995).

(13) Una política nacional urbana se define como "un conjunto coherente de decisiones derivadas de un proceso deliberado, dirigido por el gobierno nacional que coordina y reúne diversos actores para lograr una visión y objetivos comunes que fomenten un desarrollo urbano más transformativo, productivo, inclusivo, y resiliente a largo plazo" (ONU-Hábitat, 2014). Por lo que debemos entender una política nacional urbana "tanto como un proceso como por un resultado que aprovecha el dinamismo de las ciudades y la urbanización", las cuales buscan "estructurar un marco más integrado por sistemas holísticos que crean un entorno propicio para el establecimiento, la institucionalización y la mejora del desarrollo urbano y la agenda del país correspondiente" (Naciones Unidas, 2016). 
con el agua y la atmósfera, integran el sistema ambiental, a la vez que son sede de las acciones humanas que modifican, en relación de interdependencia, al propio medio.

Por eso asumimos el ordenamiento territorial en íntima relación con los temas ambientales. Vivimos una realidad impregnada por una fuerte conciencia ambientalista, pero tal aspecto pareciera desagregarse de una concepción sobre la política del suelo. Desde esta perspectiva, no podemos dejar de preguntarnos si la ciudad, si la tendencia urbana, si la configuración espacial del territorio, no constituyen un punto insoslayable de análisis. En una palabra, si podemos abordar la cuestión con una exclusiva inquietud ecológica, que irá diversificando sus intereses en los múltiples efectos que ofrece la degradación del medio ambiente urbano.

Por cierto, no asumimos esta advertencia con vocación resolutiva, solamente intentamos subrayar una interdependencia, que a nuestro criterio exige partir de la premisa del OT, para desde allí diversificar las ramas de su análisis. La contaminación, la polución ambiental, por citar algunos ejemplos, son disfuncionalidades asociadas a la organización territorial, entendida ésta como el haz de derechos y obligaciones que comprende al Estado y al individuo sobre el territorio urbano, pero también sobre la preservación espacial en su totalidad.

Ahora bien, si coincidimos sobre el concepto aludido, debemos también marcar la acusada diferencia entre el ordenamiento territorial y la actividad urbanísti$c a$. En el caso de la actividad urbanística, se trata de definir las concretas actividades que sobre el suelo pueden materializarse. En el de la ordenación del territorio se trata de precisar el marco general en que la actividad urbanística debe tener lugar. De otro lado, actividad y ordenación dan a entender que la función del gobierno enmarca necesariamente la primera, estableciendo las opciones básicas a que debe atenerse su gestión(14).

\section{Un modelo territorial}

Como hemos dicho, el ordenamiento territorial supone la manifestación espacial de una política física, económica, social, cultural y ambiental y a la vez constituye una indispensable herramienta de planificación y gestión.

En una palabra, expresa un orden regulador del destino, uso, tráfico, transformación y aprovechamiento del suelo y sus recursos, y, por lo tanto, comprende a

(14) Concebido en esa amplitud el urbanismo existe una acusada interrelación entre la ordenación territorial, la ordenación urbanística y el medio ambiente, aspectos todos ellos que conviene distinguir. La ordenación del territorio y la actividad urbanística son dos funciones públicas de indudable proyección sobre toda clase de suelos (Medina de Lemus, 1999). 
todos los órganos, normas y procedimientos que están relacionados con el funcionamiento y administración del territorio.

La concepción recién descripta tiene como objetivo reflejar un modelo territorial, en cuya potencialidad se inscriben los criterios de desarrollo sustentable que deben guiar su crecimiento.

Organizar el territorio no puede constituir un fin en sí mismo, sus objetivos están dirigidos a la estructuración del espacio en relación con el sistema de ciudades, a la expansión e integración regional y al mejoramiento de la calidad de vida de la población.

En este orden de ideas, adquiere toda su jerarquía el plan de ordenamiento territorial y ambiental, cuyos lineamientos constituyen inaplazables referencias para los planes regionales, los planes sectoriales (cultura, economía, etc.) y los planes particulares con incidencia sobre el territorio (15).

Decimos esto porque se han propiciado émulos contemporáneos del término ( v.gr: "estrategia", "directrices generales") que parecieran sustituir la laguna que ofrece esta cuestión; aún más, en los últimos simposios organizados el término se soslaya sutilmente en el marco de las recomendaciones promovidas. La decadencia de los "planes" en toda América Latina y los prejuicios sobre su configuración dogmática, parecieran favorecer esta tendencia.

Sin embargo, para nosotros el plan supone tres aspectos:

- El reconocimiento de su naturaleza jurídica que al incorporarse al plexo normativo promueva todos sus efectos.

- La necesidad de establecer sus jerarquías, que implique una verdadera coordinación y compatibilización competencial en cuanto a sus fines y cometidos de actuación sobre el territorio.

— Un ámbito de imprescindible encausamiento para la participación orgánica de la comunidad.

(15) No se puede dejar de analizar la vinculación del OT y la planificación, a pesar de que resulta curioso observar la devaluación que el término concita entre nosotros. Quizás una reminiscencia a "dirigismo", "intervencionismo", "tecnicismo" sean algunas de las asociaciones que el término promueve. Como quiera que fuere, nuestros intentos de planificación han sido pocos, erráticos y subalternizados en los tiempos de su implementación. Pero no es el caso detenernos en las causas y circunstancias que llevan a este descreimiento generalizado, sino por el contrario enfatizar que no concebimos un OT sin la figura del plan y que tal definición exige un marco administrativo - orgánico- funcional de inevitable traducción jurídica. 


\section{IV.1. Una visión territorial integrada}

Este modelo debe resolverse en la búsqueda de un equilibrio entre la regulación prospectiva y la dinámica de su operatividad. El futuro no puede ser el resultado de sucesivos presentes sino el efecto producido por una política de largo alcance, capaz de orientar la gradualidad de sus acciones.

Para ello, las políticas de organización territorial deben ser consideradas dentro del contexto institucional, económico y social, respondiendo a los requerimientos propios que presenta nuestro Sistema Federal; contemplando una "visión territorial integrada" que permita no solo la compatibilización de las distintas etapas, sino que posibilite un marco racional de asignación de recursos. Por lo tanto, la multiplicidad de aspectos intervinientes en el OT requiere de la toma racional de decisiones en el largo y mediano plazo y de acciones permanentes y concretas en el corto plazo, promoviendo una ineludible coordinación en todos los niveles jurisdiccionales; para lo cual, debemos partir de la base que el tema tiene una amplitud y complejidad que requiere aunar las distintas disciplinas e instituciones que lo informan(16).

La experiencia pone de manifiesto - en nuestro caso, participando en distintas instancias interdisciplinarias- que la cuestión genera diversas vacilaciones metodológicas y aproximaciones conceptuales que exigen conjugar el enfoque propuesto.

Es decir, nos encontramos frente a un complejo trabajo que supone aportar desde las diferentes ópticas formativas los conceptos que permitan expresar con ductilidad y precisión sus alcances.

En este sentido, la práctica indica las naturales dificultades que se presentan al intentar desbordar el carácter convencional de los tópicos que cada disciplina mantiene arraigados, muchas veces fuente de inconvenientes iniciales o estériles discusiones.

Vale aquí recordar, que, sin perjuicio de las disímiles áreas y disciplinas con competencia en la materia, la propuesta final debe concebir su tipificación jurídica,

(16) La escasez relativa de datos urbanos en la región, intensificada en la información de las diversas características sociales y habitacionales de la población que habita en condiciones de pobreza y/o en asentamientos informales y precarios, ha sido un obstáculo para el diseño y la elaboración de políticas urbanas e instrumentos de planificación urbana de calidad, debido a la limitada capacidad de analizar los desafíos de los sistemas en base de evidencia confiable. En general, la planificación urbana en la región no ha sido realizada sobre la base de investigación y análisis de datos (CEPAL y ONU-Hábitat, 2016). 
para que el proyecto se convierta en un verdadero instrumento regulador de la actividad.

Los diferentes desarrollos teóricos, las tendencias predominantes, los perfiles de análisis, los intereses doctrinarios que aporten todos los actores involucrados en la cuestión (políticos, académicos, científicos, sociales, etc.) deben confluir en un horizonte mancomunado que solo garantizará un marco jurídico, participativo, dinámico, eficaz en sus metas y operatividad.(17)

\section{Un inapelable testimonio}

Ahora bien, la concepción del Ordenamiento Territorial con el alcance aludido, ofrece desde hace varias décadas un decisivo desarrollo en el derecho comparado (Garner, J. F y Otros, 1976).

Parece pertinente recordar que, en el año 1979, el profesor García de Enterría presentaba su libro Lecciones de Derecho Urbanístico replanteando una nueva visión desde la ciencia de la administración sobre la ley del suelo española del año 1956(18).

Sobre esta materia, realizamos nuestros primeros estudios en aquella época, con la sorpresa de un tema que en nuestro país solamente se manifestaba desde un punto del programa de "Derecho público, provincial y municipal", mientras que cruzando el atlántico, constituía toda una disciplina en sí misma, abarcando numerosos tópicos a los que se sumaban nuevos y variados desarrollos doctrinarios (Sala Arquer, 1980) (19).

(17) Los principales elementos de la legislación y normativa urbana a nivel mundial no han sufrido modificaciones significativas en los últimos 20 años y en algunos casos particulares, en los últimos 40 años, manteniéndose normativas que dificultan la garantía al derecho a la vivienda, la función social del suelo y la diversidad de formas de producción de la ciudad, entre otros. Una muestra de aquello se relaciona con el bajo número de iniciativas legales tendientes a promover un marco jurídico urbano innovador y localmente relevante, en ámbitos como la planificación física y el control del desarrollo... por último, debemos agregar que la legislación urbana en países en vías de desarrollo y de transición, a menudo se caracteriza por ser altamente detallada y rígida, lo cual indudablemente tiene como consecuencia, su incumplimiento (ONU-Habitat, 2016).

(18) Esta ley, conocida abreviadamente como Ley de Suelo, y promulgada el día 12 de mayo de 1956, según señala Luciano Parejo Alfonso era fruto de la conjunción histórica de la inaplazable necesidad de racionalizar desde el interés general el proceso de urbanización generalizada y acelerada, derivada del desarrollo económico-social en una sociedad en trance de industrialización y la asunción por el Estado, como responsabilidad propia, de eso que hoy calificamos "calidad de vida", operando una juridificación completa del urbanismo sobre nuevas bases.

(19) Entre otros aportes, Sala Arquer, J. M. (1980). Aspectos jurídicos de la ordenación del territorio. Madrid: Instituto Nacional de Prospectiva, con análisis de la política de ordenación territorial en 
Cursamos la materia "Derecho Urbanístico" del doctorado de la Facultad de Derecho que dirigía el profesor Martín Bassols Coma, en un marco donde se sucedían una infinidad de actividades de capacitación y posgrado, que abarcaban distintas disciplinas con el singular protagonismo de las ciencias jurídicas.

Esa etapa de estudio nos permitió constatar una concepción en pleno y renovado desarrollo, mientras en nosotros se expresaba como una excluyente mirada de la arquitectura, con el significativo aporte de las ciencias sociales.

Con este impulso participamos en distintas iniciativas académicas, de las cuales parece ilustrativo citar las Primeras jornadas sobre Derecho y Planeamiento Urbano llevadas a cabo en nuestra ciudad en el año 1982 (20); el Primer Curso de Derecho Urbanístico realizado en nuestra facultad de Ciencias Jurídicas en el año 1986, dictado por el profesor Luciano Parejo Alfonso, que recién había publicado un voluminoso y detallado libro sobre el tema (Parejo Alfonso, 1986), o la creación e intensa actividad del Instituto de Estudios Municipales (IEM), resultado de un auspicioso Convenio entre el gobierno de la provincia de Buenos Aires, la Universidad Nacional de La Plata y el Instituto de Administración Local de España.

Un compromiso inicial, que fue perdiendo fuerza por los muchos y variados avatares que signaron nuestra vida política y, por cierto, el tema en análisis. De estos recuerdos han pasado más de tres décadas, y la literatura jurídica sobre estas cuestiones parece haber sido desalojada de la agenda pública, generando una infecunda inquietud en la finalidad que perseguimos.

Podríamos ensayar un artículo que desarrolle aquello que debería ser, con el inevitable riesgo de incurrir en un exceso teórico; o acaso, definir un catálogo de ausencias, como una ineludible muestra de un quehacer público que no contempla el uso del suelo como perspectiva fundamental de su gestión.

Pero ninguna de estas hipótesis lograría el cometido que nos hemos propuesto, pues resulta imposible ilustrar sobre una orientación sin aquellos casos específicos que lo ejemplifiquen; en consecuencia, soslayando las opciones, el camino a transitar requiere que el vigor de lo expuesto guarde relación con aquello que podemos reconocer como una vivencia cotidiana.

Alemania, Gran Bretaña y Francia; García Álvarez, A. (1981). La ordenación del territorio en el Estado de Autonomías", Estudios Territoriales. También las publicaciones del CEOTMA (1981). Ordenación del territorio. Normativa general en el Derecho comparado. Madrid y Ordenación del territorio. Normativa sectorial en el Derecho comparado. Madrid.

(20) Primeras jornadas sobre derecho y planeamiento urbano (1982), organizadas por Sección de Derecho Urbanístico y Ambiental, Instituto de Derecho Ambiental, Colegio de abogados de La Plata. 
Si las orfandades aludidas (ausencia de una ley de OT, aplicación parcial de nuestra ley provincial de suelo y una lábil normativa urbana a nivel local) nos ofrecen un panorama infértil, debemos detenernos en un punto cuyo análisis permita proyectar los distintos factores que en él convergen.

\section{V.1. Una insoslayable referencia}

En este sentido, vale rememorar aquel primer encuentro con el Dr. Eduardo García de Enterría en la sala de profesores de la facultad de Derecho de la Universidad Complutense de Madrid. Con una generosidad digna de su estatura y sencillez escuchó nuestro inaugural planteo cuando esbozamos la intención de analizar los rasgos comunes del derecho administrativo argentino y español, para lo cual desarrollamos algunas aproximaciones que fundamentaban nuestro interés.

En ningún momento corrigió ese torrente de palabras que suelen desgranarse en instancias de presentación; por el contrario, se sumó a nuestra inquietud señalando que a ese propósito podía arribarse desde un tema que inevitablemente nos llevaría a la consideración de lo planteado. Nos sugirió comenzar nuestros estudios sobre el ius edificandi frente a nuestra enmudecida mirada. No sabíamos nada sobre ese punto y nos parecía un descenso analítico, que con algún vértigo nos reubicaba en nuestra situación.

Entonces, con profunda amabilidad, reflexionó como su análisis irradiaba sobre la función social de la propiedad, los alcances de las restricciones administrativas, los índices urbanísticos aplicables, la plusvalía urbana y la naturaleza colectiva que presume la ciudad.

Nos recomendó también bibliografía, que en versión universitaria se ofrecían a un costo muy accesible en la biblioteca y nos invitó a su clásico seminario que dirigía todos los miércoles a las diez de la mañana en el Departamento de derecho administrativo de la facultad. Siempre tuve presente aquella sugerencia metodológica, que ordena el pensamiento y lo dota de plena y provechosa utilidad.

\section{V.2. Un umbral conceptual}

Entonces, ante el desconcierto normativo que suscita el tema, se nos ocurre apelar a aquella entrañable indicación y detenernos en el umbral conceptual que da sentido al tema que nos convoca. ¿A qué llamamos aptitud urbana? ¿Qué nuevos alcances y condicionamientos la redefinen? Con qué vara se mide esta situación, impregnada en la actualidad de nuevas y vitales exigencias como el derecho a la ciudad, la inclusión, el acceso al hábitat, la sustentabilidad ambiental, las 
políticas de desarrollo y tantos otros temas vinculados a las garantías que contemplan y ensanchan los Derechos Humanos.

Una realidad que en las distintas regiones y países vecinos tiene múltiples y variados enfoques, desde el sistema de ciudades, la reducción de la pobreza, las políticas habitacionales, la urbanización de los asentamientos informales o la descentralización local como responsable primario del ordenamiento territorial.

En fin, una agenda dinámica y versátil como da cuenta el último y detallado informe de CEPAL, que resulta de interesante lectura en esta materia(21).

En el contexto de la democratización de la región, diversos movimientos han logrado avances significativos en los últimos 20 años, como por ejemplo en Colombia (ley No 388 en 1997), Brasil (Ley Federal No 10.257 llamada "Estatuto de la Ciudad" en 2001), y más reciente en Ecuador (Ley de Ordenamiento Territorial, Uso y Gestión del Suelo en 2016), legislación que reconoce la función social de la propiedad y el suelo, además de entender la ciudad como producto de un proceso colectivo, donde debe existir una distribución justa de los costos y beneficios del desarrollo urbano. Estos movimientos han generado una conciencia sobre el rol central de los marcos legales, en cuanto a lograr un ordenamiento espacial y territorial más participativo, justo e inclusivo, asimismo, han logrado demostrar y poner en agenda las negativas consecuencias de mucha de la legislación urbana existente en la región, que causa la reproducción de los procesos de segregación socio-espacial e informalidad. El movimiento internacional del Derecho a la Ciudad ha buscado el reconocimiento de los derechos colectivos a la ciudad, concepto que ha emergido en las últimas décadas como concepto clave en el debate sobre el desarrollo urbano sostenible, cabe mencionar que los países de la región han estado a la vanguardia de esta discusión. El derecho a la ciudad ha sido incorporado legalmente a través de modificaciones constitucionales en Brasil y Ecuador, y a nivel de ciudad en la Ciudad de México.

\section{V.3. Una imprescindible precaución}

Pero en la provincia de Buenos Aires abordar este primer eslabón ofrece una singular complejidad, pues no podemos referirnos a nuestro extenso territorio como una expresión uniforme, ya que un sistema asimétrico de asentamientos impide afrontar el concepto de aptitud urbana desde una visión común.

Un elemental relevamiento refleja este diagnóstico: tenemos partidos que no llegan a los 10.000 habitantes y cuya tasa de crecimiento resulta de mínima

(21) Plan de Acción Regional para la implementación de la Nueva Agenda Urbana, América Latina y el Caribe (CEPAL y ONU-Habitat, 2016). 
oscilación (22); y, por otra parte, numerosos partidos que superan holgadamente los 300.000 habitantes que en el 1,2 \% del territorio bonaerense conforman el Área Metropolitana(23).

Una Provincia que como se ha señalado tantas veces, nos ofrece una bifurcación única en nuestro país y en consecuencia la necesidad de un tratamiento claro y diferenciado respecto a su indiscutible singularidad.

Para que el lector comparta el fenómeno, en nuestra provincia conviven bajo la misma legislación el municipio de Tordillo con 1.796 habitantes (proyección que para el 2021 llegaría a una tasa de crecimiento de 1.809 habitantes) y La Matanza con 2.040.000 habitantes (que para el mismo período tiene previsto llegar a 2.377.874 habitantes). En definitiva, salvo el fenómeno metropolitano, el resto de la provincia presenta tres grandes partidos (24) y algunos centros de más de 100.000 habitantes (25), en una extensión territorial de infinitas connotaciones.

Un estudio reciente del Ministerio de Economía de la Pcia. de junio del año 2016, provee un trabajo sobre "proyecciones de población por municipio Provincia de Buenos Aires 2010-2025" donde expone con precisión estos datos que resultan de significativa ilustración.

De tal forma que las necesidades y exigencias de la aptitud urbana no serán las mismas en las pujantes ciudades del interior que vertebran nuestra provincia, que en aquellos centros cuya complejidad demográfica pone en tela de juicio la falta de planificación.

Por la dimensión de su estudio, no nos abocaremos en estas líneas al Área Metropolitana, a la que ya le supimos dedicar un trabajo específico (Reca, 2002), tarea que oportunamente continuamos en el Consejo Asesor de la Comisión Consultiva del Área Metropolitana de Buenos Aires (COCAMBA), que titularizara el Dr. Facundo Suarez Lastra y cuya actual perspectiva interjurisdiccional merece detenernos en un próximo ensayo (26).

(22) General Guido (2.800), Pila (3.800), Pellegrini (5.900), Lezama (6.000), Monte hermoso (7.000), Castelli (8.500), Tres Lomas (8.650), Salto (8.700), Tapalqué (9.600), Hipólito Yrigoyen (9.900).

(23) Esteban Echeverría (337.000), Pilar (340.000), Malvinas Argentinas (343.000), Tres de febrero (343.000), Berazategui (346.000), Avellaneda (350.000), General, San Martín (421.000), Tigre (422.000), Lanús (463.000), Florencio Varela (474.000), Merlo (570.000), Almirante Brown (580.000), Quilmes (626.000), Lomas de Zamora (635.000).

(24) Bahía Blanca (307.000), General Pueyrredón (640.000), La Plata (690.000).

(25) Junín(93.000), Necochea (94.000), Pergamino (107.000), Luján(113.000), Olavarría (116.000), Tandil (132.000), San Nicolás (151.000).

(26) Decreto No 1126/2016 Artículo 2: Créase la Comisión Consultiva del Área Metropolitana de Buenos Aires (CO.C.A.M.B.A.), en el ámbito del Ministerio del Interior, obras públicas y vivienda, 


\section{Sobre la aptitud urbana}

En definitiva, asumimos la aptitud urbana como las garantías esenciales que identifican y sustentan el alcance de la residencia permanente, por ende, implica una intervención pública sobre una zona, área o asentamiento contemplando los derechos y finalidades de nuestro comportamiento ciudadano (27).

Por eso, esta disposición necesita de algunos elementales indicadores que definan su naturaleza. En la inteligencia que se trata de una perspectiva provincial, dos criterios se presentan insoslayables; nos referimos a la clasificación del territorio y al proceso de ocupación del mismo.

El primer caso se ofrece como el presupuesto básico de esta condición, y el segundo caso, como el imprescindible índice que determinará las pautas previstas para dotar al núcleo urbano de los servicios esenciales para su normal funcionamiento.

Nos detendremos en ellos en su actual redacción (sin perjuicio que dichas referencias deben ser replanteadas), pues para el fin que nos hemos propuesto, resultan de pertinente consideración.

\section{VI.1. La clasificación del territorio}

La aptitud urbana debería ser la manifestación emergente de un criterio previo de clasificación del territorio (suelo urbano, urbanizable, no urbano, rural), tipificación que ajustara su cometido a los alcances de este diagrama, vinculando los efectos jurídicos (identificación catastral, registración, medidas, mensuras, etc.) al tipo de suelo que se trate (28).

que tendrá por objeto la elaboración de proyectos de innovación institucional para el Área Metropolitana de Buenos Aires. Serán sus funciones: a) Proponer medidas dirigidas a favorecer la coordinación entre las Jurisdicciones que se asientan en el Área Metropolitana de Buenos Aires. b) Formular propuestas de políticas públicas de innovación institucional para el Área Metropolitana de Buenos Aires, que tengan como base el desarrollo humano, económico, tecnológico, ambiental y urbano.

(27) Desde otro punto de vista, de acuerdo a la FAO (1985) la vocación de la tierra puede definirse como "la aptitud de un tipo dado de tierra para un tipo de uso específico". Así, la aptitud, o vocación, de un terreno se refiere al nivel de adecuación para alguna actividad considerando las características naturales del terreno. El análisis de aptitud, o vocación de las tierras, es parte del proceso de planeación del desarrollo regional y local, porque el resultado de este análisis generará el destino del uso de tierras. Esto implica que, considerando varias actividades económicas potenciales para un terreno, las características físicas naturales del terreno son apropiadas para sólo un número más reducido de actividades económicas, lo cual es un indicador del nivel de inversión necesario para su adecuación.

(28) En España, la legislación estatal, desde sus orígenes y la autonómica, con una u otra denominación, han adoptado el sistema de clasificación de suelos para articular su régimen jurídico y consiguien- 
Por cierto, esta ponderación no tendrá que ser rígida, sino dúctil a un criterio de desarrollo de los asentamientos existentes y de los futuros a crear. No se trata de una dimensión artificial, ni del diseño de un mapa colonizador, sino de un plan rector que refleje un proyecto de crecimiento.

Así lo prevé la ley de ordenamiento territorial y uso del suelo (№ 8.912/77) en el artículo 6:

Se entiende por:

Área Urbana: la destinada a asentamientos humanos intensivos, en la que se desarrollen usos vinculados con la residencia, las actividades terciarias y las de producción compatibles.

Subárea Urbanizada: el o los sectores del área urbana, continuos o discontinuos, donde existen servicios públicos y equipamiento comunitario como para garantizar su modo de vida pleno. El o los perímetros de esta subárea comprenderán todos los sectores servidos como mínimo con energía eléctrica, pavimento, agua corriente y cloacas.

Subárea Semiurbanizada: el o los sectores intermedios o periféricos del área urbana, que constituyen de hecho una parte del centro de población por su utilización como tal, con parte de la infraestructura de servicios y del equipamiento necesario, pero que una vez completados pasarán a constituirse en subáreas urbanizadas. A este efecto deberá lograrse como prioridad el completamiento de:

a) La infraestructura de servicios y el equipamiento comunitario.

b) La edificación de las parcelas.

Áreas Complementarias: Los sectores circundantes o adyacentes al área urbana, en los que se delimiten zonas destinadas a reserva para ensanche de la misma o de sus partes constitutivas, y a otros usos específicos.

\section{VI.2. Sobre la naturaleza del loteo}

Para cumplir la finalidad antedicha, el loteo (también genéricamente un plan) no puede concebirse como un instrumento suficiente en sí mismo, pues debemos

te valoración. A tenor del artículo 7 de la ley No 6/1998 LS, el suelo se clasifica en urbano, consolidado o no por la edificación, urbanizable, o clases equivalentes reguladas por la legislación urbanística. Sin embargo, en los municipios que carezcan de planeamiento urbanístico podrán existir, de conformidad con el artículo 11 íd., sólo dos clases de suelo: urbano y no urbanizable. Medina de Lemus, M. (1999). 
saber que el carácter con que se instrumente en el espacio urbano presume una forma de desarrollo y una inevitable configuración prospectiva.

Las exigencias de esta técnica de actuación (que se ofrece en los hechos como condición básica de la materia) tendrían que remitirse a los principios que la informan (participativos, ambientales, financieros, etc.), que deberían estar previstos en el Código de ordenamiento territorial ambiental.

Desde esta precaución, nos hacemos eco de la necesidad de implementar una norma considerando todos los aspectos que ordenen, orienten y sistematicen las modalidades vinculadas al loteo (servicios, publicidad, áreas de ubicación, etc.) (29); reiterando que su oferta resultará insuficiente en tanto no plasme una genuina coordinación con una política de ordenamiento que constituya el insustituible horizonte del comportamiento público.

La experiencia arroja datos útiles sobre este tipo de iniciativas y nos expone que el loteo sin planificación, la informalidad del sistema de transporte y los intereses económicos en juego (reconversión de la tierra, subdivisión indiscriminada, etc.), constituyen un estilo de urbanización que refleja las severas descompensaciones que podemos relevar en nuestra provincia de Buenos Aires.

Por lo tanto, una ley de loteos tiene que anticipar en su regulación la filosofía de la ley de ordenamiento territorial-ambiental; es decir, vislumbrar un indicio definido, claro y gradual de los propósitos organizadores sobre el territorio.

\section{VI.3. Una confusión terminológica}

Sin embargo, la palabra "loteo" suele emplearse en las legislaciones con un sentido equivalente a los términos parcelamiento, fraccionamiento y otros homónimos; ahora bien, no se trata de una cuestión semántica sino del efectivo alcance que quiere establecerse y de los efectos jurídicos inherentes a su situación(30).

(29) Decreto ley No 9078/78. Requisitos para el loteo. Artículo 7: La propaganda mínima obligatoria deberá incluir en forma precisa: $\mathrm{h}$ ) Los servicios públicos y de infraestructura con que cuenta el loteo en materia de energía eléctrica domiciliaria, cloacas, agua corriente y transporte. Esta indicación sólo podrá efectuarse cuando su funcionamiento, realización y prestación permanente esté asegurada y aprobada por la autoridad respectiva. La existencia en la zona de conductores telefónicos o de energía eléctrica, cañerías o redes para la provisión de agua corriente, colectores cloacales o cualquier otro servicio público, no bastará a los efectos señalados, si no puede garantizarse la inmediata ampliación de la prestación de tales servicios en beneficio de las unidades de venta.

(30) En este sentido, resulta suspicaz la derogación del artículo 1 inc. c, de la ley No 24.240 del año 1993, que preveía: la presente ley tiene por objeto la defensa de los consumidores o usuarios. Se encontraban amparados por la misma: "la adquisición de inmuebles nuevos destinados a vivienda, 
Si coincidimos que todo loteo tiene una ineludible naturaleza urbana, debemos considerar que su finalidad es la preservación, desarrollo y mejoramiento del medio ambiente urbano, y ello implica una clara subdivisión de la tierra en su aptitud actual y potencial para definir su uso y ocupación.

Podemos aquí realizarnos una pregunta que justifique esta posición: si el loteo tiene una finalidad urbana, ¿podemos realizar el mismo sin una previa clasificación del territorio que garantice esta condición? Y la respuesta sería claramente no.

Por eso, parece necesario diferenciar el fraccionamiento y el loteo, como dos modalidades que requieren de una regulación singular y a la vez complementaria. Va de suyo, que un área de explotación rural o semirrural no guarda equiparación con un asentamiento humano y esta elemental diferenciación nos reclama metas y preceptos diferentes; es decir, exige la clasificación del territorio como modalidad indispensable donde remitir sus alcances.

Por lo tanto, es importante insistir en la diferencia entre loteo y fraccionamiento: estableciendo para el primer caso una inescindible aptitud urbana (actual o potencial) y para la segunda tipología una amplitud de usos que excluyen la finalidad urbana. Por eso las exigencias que se establecen para todo loteo (servicios, equipamiento comunitario, etc.), en el segundo caso se manifiestan como promesas, es decir no constituyen necesariamente una restricción, sino una condición del dominio que se ostenta.

También debemos hacer una observación entre el parcelamiento y el loteo, estableciendo las diferencias de ambas modalidades.

Por parcelamiento entendemos cualquier clase de división del terreno, por loteo todo parcelamiento de tierra con el fin de crear nuevas áreas urbanas y/o ampliar la ya existente, con aperturas de calles o vías, con la creación o provisión de espacios libres, verdes, de utilidad pública y la realización de determinadas obras de infraestructura.

Con esta observación, queremos subrayar una diferencia sustancial, la relación que existe de género a especie entre el parcelamiento y el loteo, cuestión que merece en consecuencia un análisis particular, y resulta punto de partida indefectible para cualquier legislación al respecto (31).

incluso los lotes de terreno adquiridos con el mismo fin, cuando la oferta sea pública y dirigida a persona indeterminada".

(31) Decreto ley No 10703/10. Título III - Parcelamiento y subdivisión del suelo, cargas públicas y provisión de servicios. Sección A. Parcelamiento y subdivisión del suelo. Artículo 34: a - Parcela: bien inmueble de extensión territorial continua, deslindada por una poligonal cerrada, perteneciente a 
No debemos olvidar que el loteo es un parcelamiento de tierra con el fin de crear nuevas áreas urbanas y/o ampliar las ya existentes. Por ende, resulta inevitable asociar su naturaleza con principios e institutos propios del ordenamiento territorial, en el marco de la legislación y competencias que tiene la provincia, como, por ejemplo, las exigencias previstas para la creación y ampliación de núcleos urbanos.

\section{VI.4. Sobre la ocupación del territorio}

En cuanto al proceso de ocupación del territorio, la ley prevé el siguiente alcance:

Artículo 15: Toda creación de un núcleo urbano deberá responder a una necesidad debidamente fundada, ser aprobada por el Poder Ejecutivo, a propuesta del municipio respectivo, por iniciativa de entidades estatales o de promotores privados, y fundamentarse mediante un estudio que, además de tomar en cuenta las orientaciones y previsiones del respectivo plan regional, contenga como mínimo:

a) Justificación de los motivos y necesidades que indujeron a propiciar la creación del nuevo núcleo urbano, con una relación detallada de las principales funciones que habrá de cumplir dentro del sistema o subsistema urbano que pasará a integrar.

b) Análisis de las ventajas comparativas que ofrece la localización elegida en relación con otras posibles y la aptitud del sitio para recibir los asentamientos correspondientes a los diferentes usos.

c) Evaluación de la situación existente en el área afectada en lo relativo a uso, ocupación, subdivisión y equipamiento del suelo.

d) Demostración de la existencia de fuentes de aprovisionamiento de agua potable en calidad de cantidad para satisfacer las necesidades de la población potencial a servir.

e) Comprobación de la factibilidad real de dotar al nuevo núcleo urbano de los servicios esenciales para su normal funcionamiento.

f) Plan Director del nuevo núcleo urbano conteniendo como mínimo:

- Justificación de las dimensiones asignadas al mismo, así como a sus áreas y zonas constitutivas, con indicación de las densidades poblacionales propuestas.

un propietario o varios en condominio y aunque hayan sido adquirido por más de un título, cuya existencia y elementos esenciales constan en un plano registrado. 
- Trama circulatoria y su conexión con los asentamientos urbanos del sistema o subsistema al cual habrá de incorporarse.

- Normas sobre uso, ocupación, subdivisión, equipamiento y edificación del suelo para sus distintas zonas.

— Red primaria de servicios públicos.

— Localización de los espacios verdes y reservas de uso público y su dimensión según lo dispuesto por esta ley.

g) Plan previsto para la prestación de los servicios esenciales y dotación de equipamiento comunitario.

\section{Otros aspectos a considerar}

Pero la aptitud urbana no se agota en las condiciones habilitantes del lote, otros factores tienen una incidencia que pueden comprometer seriamente la presunción de su naturaleza. Nos referimos al contexto en que se asienta y las características que el mismo presenta.

\section{VII.1. Sobre el contexto}

Si en el lugar de emplazamiento, hay terrenos u obras abandonadas, o se construye un edificio de un volumen desproporcionado, las posibilidades de afectación son innumerables; cualquiera que haya transitado esta experiencia podría recrear las variadas situaciones que pueden producirse, desde la ocupación del lote por terceros en una irregularidad manifiesta que se extiende en idénticas conductas, hasta la construcción clandestina que sin permiso alguno, va generando invasiones o daños de todo tipo en un espiral sin control.

La aptitud urbana debe tener un alcance contextual, asociado a la zona donde esta condición resulta predominante, para ello la residencia permanente exige una tutela sobre este tipo de finalidad que, naturalmente exceden los problemas de vecindad (32), mucho más cuando estos episodios se presentan sobrevinientes, frecuentes y claramente incausados. Debemos tener presente que inclusión no es intrusión.

(32) Código Contravencional de la Municipalidad de La Plata (Ordenanza No 6147. Año 1985) que, entre otros ejemplos, contempla: la ejecución de demoliciones de inmuebles sin permiso municipal; el desagüe de piscinas en la vía pública; el depósito en la vía pública de residuos domiciliarios en recipientes inadecuados, etc. 
La tolerancia y/o desidia por parte de la autoridad de aplicación suele transferir la carga de la prueba al afectado, en una constante acreditación de testimonios y conjeturas que alcanzan un grado de especial inestabilidad, que finalmente pone en vilo no solo el valor de la propiedad sino también su propio afincamiento.

No se trata de un tema de faltas, sino de un severo perjuicio que en oportunidades pareciera guiarse por otros propósitos, que exigen con urgencia el establecimiento de pautas de convivencia urbana.

Las legislaciones avanzadas establecen plazos, restricciones y multas ante estas circunstancias, pues está claro que la aptitud urbana es una obra eminentemente colectiva que debe resguardarse a favor del interés público en juego (Medina de Lemus, 1999)(33).

\section{VII.2. Sobre la funcionalidad}

Otro aspecto fundamental para garantizar esta aptitud es el equipamiento urbano, esa condición invisible que dota al terreno de todas las exigencias que su construcción demanda.

Nos referimos a la funcionalidad, que en materia de propiedad horizontal modalidad prevalente para multiplicar el coeficiente habitacional - requiere indefectiblemente ajustar el nuevo factor de ocupación con todos los servicios esenciales, pues en general esta transformación se ha realizado a partir de una vivienda unifamiliar, cuya infraestructura se ajustaba a una determinada demanda.

Pues bien, resulta imprescindible que la construcción en altura guarde proporcionalidad con la construcción subterránea, contemplando los servicios esenciales (provisión de agua potable, eléctrica, desagües, cocheras, etc.) que den razón a esta nueva morfología (34).

(33) Se entiende por Disciplina Urbanística (DU) el ejercicio de las potestades administrativas encaminadas a proteger la legalidad urbanística, definir las conductas que suponen infracción y sancionarlas, restableciendo la legalidad quebrantada. El artículo 19 LS establece que los propietarios de toda clase de terrenos y construcciones deberán destinarlos a usos que no resulten incompatibles con el planeamiento urbanístico y mantenerlos en condiciones de seguridad, salubridad y ornato público. Quedarán sujetos igualmente al cumplimiento de las normas sobre protección del medio ambiente y de los patrimonios arquitectónicos y arqueológicos y sobre rehabilitación urbana. Medina de Lemus, M. (1999).

(34) Decreto ley No 9240/79. Propaganda y publicidad" Artículo 1: La propaganda mínima obligatoria, exigida por la presente ley, que se realice para promover la venta de tierras provenientes de subdivisiones o mensuras, loteos o fraccionamientos ubicados en jurisdicción de la provincia de Buenos Aires, ya sea en forma particular o remate, deberá contar con la previa aprobación de la Dirección de Geodesia del Ministerio de Obras Públicas, quedando sujeta a las disposiciones de esta ley. 
Pero esta fundamental previsión, en muchas oportunidades se exceptúa con motivo de "premios" o "compensaciones" (35) que terminan desvirtuando los cometidos citados. Las propias ordenanzas suelen establecer estas modalidades con argumentos de marginal ponderación, configurando un alarmante déficit que afecta de forma insoluble la "calidad de vida".

A estos fines, la ecuación resulta sencilla pues si donde había una vivienda unifamiliar se emplaza un edificio de 15 pisos con 4 departamentos por planta, es inevitable deducir que estará habilitado para 60 familias y en consecuencia debería contar con la posibilidad de garantizar efectivamente todos los servicios aludidos. Para ilustrar lo dicho, en una referencia inmediata y palpable, también debería prever la guarda de idéntico número coches, considerando el ajustado promedio de un automóvil por unidad funcional. Pero esto no es así y un arbitrario remanente atosiga las calles, desbordando la trama circulatoria en una densidad de complejas consecuencias.

No está ajeno a este sencillo ejemplo la recurrencia de un comportamiento que influye en este tipo de habilitaciones bajo el ánimo de una sórdida especulación, un constante desvío que desnaturaliza el ius edificandi, saturando las funciones y actividades colectivas, como cuando se demuele una casa patrimonial, con el sencillo recurso de retirar una placa de acrílico o cerámica y, en todo caso, la exclusión del catálogo respectivo (36).

\section{VII.3. Sobre la comunicación}

La aptitud urbana también infiere comunicación, como modo inherente a su condición; si esta no está, el asentamiento se desarticula en una anárquica segregación que fractura su propia naturaleza.

(35) Decreto ley No 2418/11 que, en sus Considerandos, reza: Que sin perjuicio de lo establecido en la normativa provincial respecto del Ordenamiento Territorial y Uso del Suelo puede la Comuna auspiciar modos para estimular la mejor arquitectura en la ciudad, incentivando y beneficiando mecanismos de compensaciones para aquellos proyectos que incorporen resultados que objetivamente optimicen las morfologías resultantes en el paisaje urbano.

(36) Que atento a la Resolución de la Suprema Corte de Justicia de la provincia de Buenos Aires en la causa I 71446 y el decreto No 1525/11, la Municipalidad de La Plata asume el compromiso de impedir la destrucción, distorsión o demolición de cualquiera de los bienes inmuebles incluidos en el catálogo que forma parte de los decretos № 1579/06 y No 1592/08 y en el que a fututo le suceda, todo ello en el marco de la protección del patrimonio arquitectónico del caso fundacional, generando acciones tendientes a evitar la pérdida irreversible de estos bienes. Que de esta manera se procede a proteger a todos aquellos bienes que detenten grados de protección patrimonial por formar parte del catálogo actualmente vigente y a todos aquellos que integren el Registro Único de Bienes establecido por ordenanza № 10.703 . 
La comunicación es el sustento ontológico de nuestro comportamiento social, la expresión inclusiva, la validación pública, el ritmo del intercambio, el sentido del encuentro, la configuración de nuestra individualidad colectiva. Nada de esto se cumple si la suma de impedimentos o dificultades genera un cautiverio compulsivo.

Una cosa es la decisión de vivir en un barrio cerrado, que en principio posibilita un tipo de convivencia donde se privilegian otros factores (seguridad, espacios verdes, estilo de edificación) y otra muy distinta, un asentamiento urbano en estado de trombosis, desconectado de la red asistencial; pues la comunicación no solo supone la frecuencia del servicio público de transporte, sino también el acceso a otro tipo de elementales prestaciones (sanidad, educación, seguridad) que garanticen su condición.

\section{VII.4. Un catálogo de insuficiencias}

Las insuficiencias reseñadas forman parte del lenguaje del acostumbramiento. A nadie parece llamarle la atención esas viviendas aisladas de todo servicio, o esas familias acechadas por un contorno disfuncional, o las reiteradas ordenanzas urbanas que se aprueban en la madrugada con voluntades sorpresivas. Es decir, la persistencia de un colapso cuyas causas se recrean y multiplican en distintas escalas.

En este marco, el poder público se presenta "conciliador" frente a los escenarios referidos, como si se tratara de una forma manifiesta de asistencia y reactivación o lo que se ha dado eufemísticamente se ha dado en llamar "la ciudad en movimiento".

En todo caso la suerte la corren los ciudadanos, que estupefactos corroboran los vicios redhibitorios de esa construcción, la falta de equipamiento suficiente $\mathrm{u}$ otras severas deficiencias como las recién aludidas. Una multitud de familias empiezan a sufrir cotidianamente estas limitaciones, que alteran sus elementales previsiones y se integran con la fuerza de una fatiga crónica.

No son impresiones extraídas de una reflexión original, son episodios comunes, reiterados, que cualquiera puede constatar. En fin, graves situaciones que constituyen el reflejo de un comportamiento anómico, en oportunidades inescrupuloso y lábil por parte de la autoridad de aplicación.

A estas disfuncionalidades se suman profusos fraccionamientos de tierra para conformar distintos tipos de barrios cerrados y numerosos asentamientos informales, generando una nueva configuración territorial; anverso y reverso de un fenómeno al que aludiremos. 


\section{Bibliografía}

CEPAL (2016). Hábitat. Plan de Acción Regional para la implementación de la Nueva Agenda Urbana para América Latina y el Caribe. ONU.

García de Enterría, E. (1979). Lecciones de Derecho Urbanístico. Ed. Civitas.

García de Enterría, E. (1979). Lecciones de Derecho Urbanístico. Ed. Civitas.

Garner, J. F. y Otros (1976). Derecho de la planificación territorial en la Europa Occidental. Ed. Instituto de Estudios de administración local Madrid.

Licia Ríos, M. G. (2017). Capacidades estatales y políticas de ordenamiento territorial - Municipios de la Provincia de Buenos Aires en el contexto pos-neoliberal (2003-2015). Dir. Bono. (FAU) Universidad Nacional de La Plata. Jurados: Prof. David Kullock (UBA), Dra. Isabel Martínez San Vicente (UNR) y Ricardo Pablo Reca (UNLP).

López Ramón, F. (1995). Estudios Jurídicos sobre Ordenación del Territorio. Ed. Aranzadi.

Losa, N. O. (1995). Reformas constitucionales y municipios. Diario La ley.

Medina de Lemus, M. (1999). Derecho urbanístico. Ed. J. M. Bosch editor.

Parejo Alfonso, L. (1986). Derecho Urbanístico - Instituciones básicas. Ed. Ciudad Argentina.

Reca, R. P. (1999). La transparencia estatal. Revista de la Fundación Ricardo Rojas. Incorporado a Reflexiones sobre el régimen municipal bonaerense. La Plata: Ed. Platense.

Reca, R. P. (2002). El ordenamiento territorial. Derecho Urbanístico. Volumen (II - III).

Reca, R. P. (2012). Una reflexión sobre el patrimonio cultural tangible. A propósito de la acción de inconstitucionalidad contra la Ordenanza 10.703 de la municipalidad de La Plata. Revista Anales. Buenos Aires: La ley.

Reca, R. P. (2015). La situación del municipio en la provincia de Buenos Aires crónica de una involución. Revista Anales. Buenos Aires: La ley.

Reca, R. P. (2015). Veinte años de la Convención Constituyente Bonaerense - La impostergable deuda del Capítulo Municipal. SeDiCi. 
Sala Arquer, J. M. (1980). Aspectos jurídicos de la ordenación del territorio. Madrid.

Scotti, E. (1979). Atribuciones y responsabilidades municipales en la ley 8912. Asesoría General de Gobierno Provincia de Buenos Aires.

\section{Jurisprudencia}

Mendoza, B. S. y Otros c/ Estado Nacional y otros s/ daños y perjuicios (daños derivados de la contaminación ambiental del Río Matanza - Riachuelo). CSJN.

Fecha de recepción: 30-03-2019 Fecha de aceptación: 05-09-2019 
